$\xi=-1$

\title{
Development of Performance Measurement Framework for Supply Chain in Desalination Industry using AHP
}

\author{
${ }^{1}$ Zulkifli M. Nopiah, ${ }^{2}$ Hasan Balfaqih and ${ }^{1}$ Nizaroyani Saibani \\ ${ }^{1}$ Department of Mechanical and Material Engineering, Faculty of Engineering and Built Environment, Universiti Kebangsaan \\ Malaysia, 43600 Bangi, Selangor, Malaysia. \\ ${ }^{2}$ Mechanical Engineering Departments, College of Engineering, Taif University, 26571 Taif, Saudi Arabia \\ *Corresponding Author Email: zmn@ukm.edu.my
}

\begin{abstract}
The concern regarding desalination technology has been rising gradually for the last years because of the enlarged need for drinkable water worldwide. Yet, there are not many studies concerned assessing the seawater desalination supply chain (WDSC) from end to end. Therefore, the objective of this paper is to propose a framework which is intended to assess the performance of WDSC. Different desalination and supply chain performance criteria and metrics have been revised and distributed into financial, social, operation, and environmental perspective. The performance criteria and metrics have been further revised by a panel of experts using Delphi-AHP technique. A weight factor has been allocated to every perspective, criteria and metric based on its importance to the WDSC. The proposed framework could serve as a reference for the researchers in desalination industry. The proposed framework would be helpful for both academics and practitioners.
\end{abstract}

Keywords: Supply Chain; Desalination; Performance Measurement; AHP.

\section{Introduction}

Water is one of the most important substances on planet earth. It is essential for human being, plants, and animals as well as in the manufacturing process of most products. Humans can live three days only without water, though it is possible to live weeks without food [5]. Plants need water in several processes including photosynthesis, transpiration, support system and nutrient distribution. Without a sufficient amount of water, plants may not grow well and might even die. In industry, water is used to transport, wash, dilute, cool down and produce materials such as papers and chemicals. In short, if there was no fresh water there would be no life on earth.

The global population has been growing rapidly in the last few centuries with current growth rate of $1.1 \%$ and world population of 7.4 billion (Population Reference Bureau 2016). This indicates a sharp increase in the population comparing to 1 billion people in $1800,2.5$ billion people in 1950, and 6.5 billion people in 2005 (Population Reference Bureau, 2013). According to the United Nations, the world population is anticipated to reach 8.5 billion by 2030, 9.7 billion in 2050 and 11.2 billion in 2100 (World Population Prospects, 2015). The continuous growth of population increases the necessity to find a renewable source of fresh water to satisfy the municipal, agricultural, and industrial needs. This is due to the limited availability of freshwater sources in earth planet.

The efficiency of a WDSC in achieving its objectives can be determined by the evaluation of its functional performance. However, this evaluation is extremely complex because it depends on a variety of parameters such as harmful emissions, energy cost, failure rates of supply pumps, power outages, and flow capacity of transmission mains [4]. Therefore, measuring the performance of a WDSC is not a straightforward task, since it can be perceived from different viewpoints and variety of parameters which are not usually quantifiable.

The current research cannot reasonably find complete answers to the list of the most inconvenient problems. Rather, this research seeks to establish a broad perspective for the evaluation of a WDSC. Many of the current assessment approaches in desalination and distribution systems focus partially on one aspect of the WDSC. As a result, their outputs often represent effectively only a part of the complete perspective and they are unable to evaluate other important aspects. This research aims to provide a more comprehensive perspective on the performance assessment of WDSC as a whole system.

Technical, economic, social and environmental performance of various scales of WDSC options such as truck distribution, wastewater treatment, desalination and rainwater tank were examined in the literature using a range of diverse quantitative and qualitative methods. These methods include mathematical optimization [2], multi-criteria decision analysis, sustainability analysis, specific net present value, and statistical analysis [3]. These techniques were applied to several case studies in developing and developed countries. While these studies have acknowledged the importance of enhancing the WDSC performance, there is a lack of performance measures and metrics which consider the whole WDSC. Hence, this study developed a performance measurement framework (PMF) to analyse the performance of WDSC. 


\section{Background}

\subsection{Seawater Desalination:}

Although water composes almost $71 \%$ of the globe, fresh water scarcity is one of the most significant issues worldwide. This is because oceans (saline water) hold about 97.5 percent of the whole water distribution, while fresh water accounts for 2.5 percent only and of the total freshwater, more than 68 percent is locked up in ice and glaciers while 30 percent of the freshwater is ground water. More than 20 percent of the population (1.2 billion people) worldwide lives in areas where physical access to water is limited (World Population Prospects 2015). Desalination refers to a water treatment process which separates salts from water. It is also called desalting or desalinization. Over decades, there is a remarkable increase in the global demand for freshwater to satisfy the needs of growing populations and economies. A sharp increase in the number of desalination plants constructed worldwide is indicated. In 1980, desalination plants produce around 5 million $\mathrm{m}^{3} / \mathrm{d}$ of freshwater. This number increased to reach 52 million $\mathrm{m}^{3} / \mathrm{d}$ from 14,000 plants in 2008 , while in 2012 it become 79 million $\mathrm{m}^{3} / \mathrm{d}$ from 16,000 plants globally (IDA, 2016). According to [8], the total capacity of desalination is expected to increase at annual rate of $9 \%$ for the period from 2010 to 2016

\subsection{Water Desalination Supply Chain Performance Measurement.}

The tremendous success of supply chain management (SCM) in manufacturing and service industries makes it attractive to be adopted in water desalination industries. SCM has been significant topic in both manufacturing and business for the last three decades. Its contribution to achieve customer satisfaction and business success has been proved by several studies. Furthermore, SCM can enhance efficiency, and decrease the total operating costs. Since competitive advantage is determined based on SCs rather than single companies, it is vitally important that SCs performance are frequently measured to enhance its performance hence strengthen its competitiveness. The significance of SC performance analysis is proven by the quantity of research in the field [6]. Vast interest has been presented in the water desalination research to enhance the efficiency of a sole desalination plant. Nevertheless, less attention has been paid to assist in improving the performance of the entire SC of water desalination starting from acquiring seawater until delivering potable water to consumers. The average water loss is one of the examples of performance inefficiency in the water distribution system which exceeds $36 \%$ in Brazil [11]. According to [1], the water losses rates in the water distribution systems ranges from 30-40\% over the world. In Europe for instance, the volume of unaccounted water ranges from $9 \%$ to $30 \%$.

\section{Methodology}

Firstly, problems were recognized from exploratory review of the literature. This process comprised stages of revision of the original ideas until gaps were determined within the research interest area. The literature review concentrated on two broad areas: water desalination supply chains; and supply chain performance measurement. Then, the collected performance metrics were distributed into financial, customer, internal processes, and environmental dimensions. Thereafter, the preliminary PMF of the WDSC was proposed. In the next phase, the developed PMF was examined and validated by a panel of experts to collect potential suggestions or amendments for each performance criterion and metric. Moreover, AHP survey questionnaires were distributed to the panel of experts to identify the relative weights of performance criteria and metrics. The multidisciplinary panel of experts from both industrial and academic backgrounds was constituted for this intent. For the industrial perspective, panel members were selected from the top management of their companies or among employees whom report directly to the top management and work in a WDSC. For the academic perspective, the panel includes scholars whose research interest areas were primarily focused on water supply, desalination or performance measurement issues. The Delphi-AHP technique, as shown in Fig.1, provides a more precise description of the decision making process.

\subsection{Delphi Technique.}

When proposing new metrics, it is significant to demonstrate their validity. Nevertheless, it is difficult to prove the validity of a particular metric. [9] Suggested using experts' agreement to validate new performance metrics. There are several methods intended to gather experts' opinion and judgment. The Delphi technique is one of these methods which was chosen because of its broad application, approval, and suitability to achieve the research objectives [10]. Delphi technique is a structured process to gather knowledge from a panel of experts in the field of study via questionnaire survey instruments [15]. Each expert individually responds to the questionnaire. Thereafter, the investigator compiles the group's responses, and resubmits the compilation to each expert for refinement purpose. Every resubmission to the panel of experts is deemed a "round". The process carries on until a consensus is attained. Approximately 10 to 15 experts are sufficient in the Delphi technique when a group is homogeneous [15]. In this study, 46 invites were sent by email with cover letter. Thirteen experts (28\%) agreed to participate in the study. A typical Delphi study is completed in 2-5 rounds [10]. For this study, the survey was completed in two rounds. The preestablished performance metrics were refined through a twostaged survey, referred to in this study as the first round and second round, in establishing the proposed PMF.

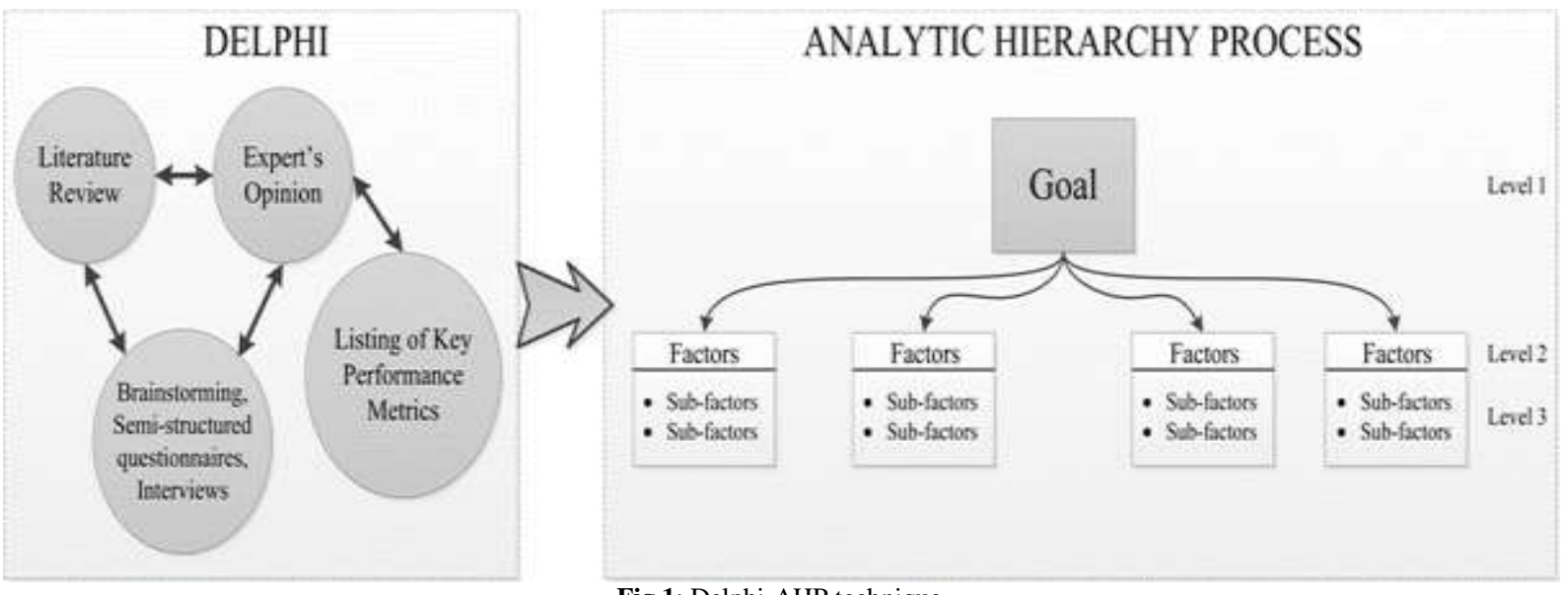

Fig.1: Delphi-AHP technique 


\subsection{Analytic Hierarchy Process.}

This research proposes the use of AHP technique to calculate the performance perspective, criteria and metrics' priorities of WDSC. The AHP is a multi-dimensional decision making method to prioritize factors by grouping them into categories and subcategories, through implementing pairwise comparisons, and through developing a logical framework of quantitative and qualitative knowledge, so that researchers could measure intangible domains. In addition, it is an instrument supported by simplified mathematics, which allows decision makers to explicitly weigh tangible and intangible criteria against each other for the purpose of resolving conflict or setting priorities. The eigenvector, relative weight, of the matrix indicates the priority order. Decision makers can calculate the consistency ratio (CR) as the ratio of the consistency index (CI) to the random index. According to [13], a consistency ratio of less than 0.1 is acceptable. If the CR is greater than 0.1 , decision makers need a refinement of the judgment metric.

\section{Results and Discussion}

68 desalination and water supply experts have been identified as the Delphi expert panellists based on years of experience, managerial positions and publications. 18 experts responded to the invitation while 13 experts participated in the first round and 11 experts participated in the second round as shown in Table 1.

Table 1: Responses to the Delphi study from direct invitations

\begin{tabular}{|l|l|l|l|}
\hline Delphi Round & $\boldsymbol{N}$ Invited & $\boldsymbol{N}(\%)$ Responses & $\boldsymbol{N}(\%)$ Participated \\
\hline $1^{\text {st }}$ & 68 & $18(26 \%)$ & $13(19 \%)$ \\
\hline $2^{\text {nd }}$ & 13 & $11(84 \%)$ & $11(84 \%)$ \\
\hline
\end{tabular}

After the first round, the environmental perspective and some performance criteria and metrics were added while other items were excluded based on the experts' recommendation. The objective of the second round is to verify the consensus of the experts and the reliability of the performance criteria and metrics for each perspective. After the second round of survey, the consensus has been reached and the final PMF for WDSC developed from this study is presented in Fig.2. The second phase is the AHP weighting calculation. A pairwise comparison among the performance perspectives has been carried out to obtain their relative priority weights. Financial perspective $(0.438)$ was rated as the most important perspective followed by the social perspective (0.352), operational perspective (0.139), and environmental perspective (0.071). All CRs were found to be $\leq$ 0.1 , thus acceptable [13]. Additional pairwise comparisons have been performed to obtain the relative weights of the remaining performance metrics under each performance criteria as illustrated in Tables 2-5.

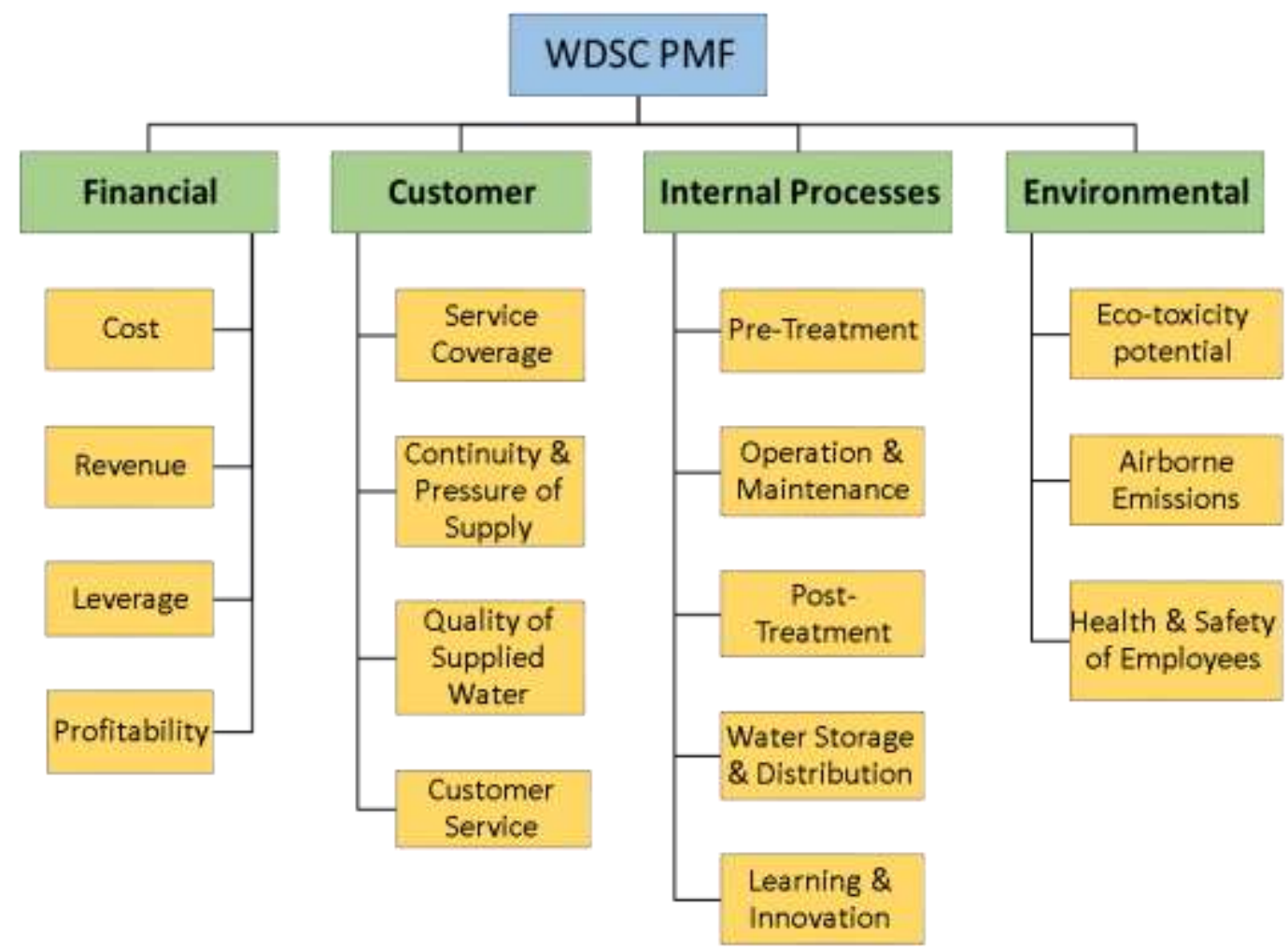

Fig.2: The WDSC performance measurement framework

For the financial perspective, profitability $(0.550)$ is found to have the highest priority under performance criteria level followed by cost (0.254), leverage (0.104), and revenue (0.092). According to the priorities of the four performance criteria under social perspective, quality of supplied water (0.316) was rated as most important criteria followed by continuity \& pressure of supply (0.281), service coverage (0.272), and customer service (0.1). At performance criteria level of the social perspective, water storage $\&$ distribution $(0.287)$ is perceived to be the most preferred criteria followed by learning \& innovation (0.236), operation \& maintenance $(0.185)$, post-treatment $(0.163)$ and pre-treatment (0.096). For decades, researchers and practitioners are concerned about the high cost of desalination process. However, water losses whether it was due to leakage or overflows or due improper maintenance performance have high effect as well. This is because the whole attempts in reducing the cost of desalination are lost due to the low performance of water distribution stage. 
Table 2: The importance weights of financial performance criteria and metrics

\begin{tabular}{|l|l|}
\hline Criteria & Metrics \\
\hline Cost $(0.254)$ & Site preparation $(0.080)$ \\
& Water intake system $(0.031)$ \\
& Desalination process system $(0.152)$ \\
& Storage system $(0.051)$ \\
& Distribution system $(0.121)$ \\
& Energy $(0.152)$ \\
& Chemicals \& supplies $(0.031)$ \\
& Operating \& maintenance $(0.168)$ \\
\hline Revenue (0.092) & Manpower $(0.105)$ \\
& Water loss $(0.109)$ \\
\hline Leverage (0.104) & Sales revenue $(0.7)$ \\
& Other revenue sources $(0.3)$ \\
\hline Profitability (0.550) & Debt service coverage ratio $(0.5)$ \\
& Debt equity ratio $(0.5)$ \\
\hline & Internal rate of return $(0.443)$ \\
& Return on net fixed assets $(0.169)$ \\
\hline
\end{tabular}

Table 3: The importance weights of social performance criteria and metrics

\begin{tabular}{|l|l|}
\hline Criteria & Metrics \\
\hline Service coverage $(0.272)$ & $\begin{array}{l}\text { Households \& businesses coverage }(0.4) \\
\text { Population Coverage }(0.6)\end{array}$ \\
\hline Continuity \& pressure of supply (0.281) & $\begin{array}{l}\text { Water interruptions }(0.7) \\
\text { Pressure of supply adequacy }(0.3)\end{array}$ \\
\hline Quality of supplied water $(0.347)$ & pH level $(0.339)$ \\
& Hardness $(0.239)$ \\
& TDS concentration $(0.281)$ \\
& Turbidity $(0.141)$ \\
\hline Customer service $(0.100)$ & Customer satisfaction $(0.441)$ \\
& Customer complaints $(0.143)$ \\
& Response to complaints $(0.289)$ \\
& Customer query time $(0.127)$ \\
\hline
\end{tabular}

Table 4: The importance weights of operational performance criteria and metrics

\begin{tabular}{|c|c|}
\hline Criteria & Metrics \\
\hline Pre-treatment $(0.096)$ & $\begin{array}{l}\text { Disinfection }(0.118) \\
\text { Biofouling control }(0.324) \\
\text { Acid treatment }(0.097) \\
\text { Coagulation }(0.178) \\
\text { Removal of suspended solids }(0.283)\end{array}$ \\
\hline Operation \& Maintenance $(0.218)$ & $\begin{array}{l}\text { Desalination plant utilization }(0.199) \\
\text { Desalinated water storage capacity }(0.105) \\
\text { Energy intensity }(0.108) \\
\text { Energy recovery }(0.206) \\
\text { Inspection of physical assets }(0.230) \\
\text { Rehabilitation of physical assets }(0.152)\end{array}$ \\
\hline Post-treatment $(0.163)$ & $\begin{array}{l}\mathrm{pH} \text { adjustment }(0.327) \\
\text { Addition of corrosion inhibitors }(0.155) \\
\text { Hardness adjustment }(0.203) \\
\text { Disinfection }(0.215) \\
\text { Blending with fresh water }(0.100)\end{array}$ \\
\hline Water storage $\&$ distribution $(0.287)$ & $\begin{array}{l}\text { Storage tank cleaning }(0.136) \\
\text { Connection repair time }(0.192) \\
\text { Time to install a customer meter }(0.089) \\
\text { Water losses }(0.346) \\
\text { Active leakage control }(0.237)\end{array}$ \\
\hline Learning \& Innovation (0.236) & $\begin{array}{l}\text { Research budget }(0.175) \\
\text { Training budget }(0.330) \\
\text { Internal training }(0.207) \\
\text { External training }(0.288)\end{array}$ \\
\hline
\end{tabular}

Table 5: The priority weights of environmental performance criteria and metrics

\begin{tabular}{|l|l|}
\hline Criteria & Metrics \\
\hline Eco-toxicity potential $(0.332)$ & Waterborne emission $(0.8)$ \\
& Emissions to soil $(0.2)$ \\
\hline Airborne emissions $(0.527)$ & Global warming $(0.22)$ \\
& Ozone depletion $(0.325)$ \\
& Acidification $(0.27)$ \\
\hline Health \& safety of employees $(0.141)$ & Eutrophication $(0.185)$ \\
& Working accidents $(0.110)$ \\
& Medical treatment case $(0.175)$ \\
& Safety awareness $(0.371)$ \\
\hline
\end{tabular}




\section{Conclusion}

This study has been developed in order to develop a PMF to evaluate and ultimately enhance the SC performance in seawater desalination industry. Moreover, it will serve as a framework for the decision makers in planning new desalination plants beyond the financial perspective. The proposed approach combines the literature analysis of performance measurement in SCM, desalination, and water resource management together with the knowledge extracted from experts using the Delphi technique. Moreover, the AHP technique is employed to determine the priority and relative weights of each performance criterion and metric. The results of the Delphi technique and the AHP comparison have been discussed.

\section{References}

[1] Araujo, L.S., Ramos, H. and Coelho, S.T., 2006. Pressure control for leakage minimisation in water distribution systems management. Water Resources Management, 20(1): 133-149.

[2] Al-Nory, M.T. and Graves, S.C., 2013. Water desalination supply chain modeling and optimization: case of Saudi Arabia. IDA Journal of Desalination and Water Reuse, 5(2), pp.64-74.

[3] Balfaqih, H., Nopiah, Z.M., Saibani, N. and Al-Nory, M.T., 2016. Review of supply chain performance measurement systems: 1998-2015. Computers in Industry, 82, pp.135-150.

[4] Ghaffour, N., Missimer, T.M. and Amy, G.L., 2013. Technical review and evaluation of the economics of water desalination: current and future challenges for better water supply sustainability. Desalination, 309, pp.197-207.

[5] Gleick, P. H. 1996. Basic water requirements for human activities: meeting basic needs. Water international, 21(2), 8392.

[6] Gopal, P.R.C. and Thakkar, J., 2016. Sustainable supply chain practices: an empirical investigation on Indian automobile industry. Production Planning \& Control, 27(1), pp.49-64.

[7] IDA, 2016. International Desalination Association Desalination Yearbook 2016-2017. Media Analytic Ltd.: Oxford, UK.

[8] Isaka, M. 2012. Water desalination using renewable energy. International Renewable Energy Agency.

[9] Kaufman, J. C., J. Baer, J. C. Cole \& J. D. Sexton 2008. A comparison of expert and nonexpert raters using the consensual assessment technique. Creativity Research Journal 20(2): 171178.

[10] Linstone, H. A. \& M. Turoff. 2002. The Delphi method: Techniques and applications Ed. 18. Addison-Wesley Publishing Company, Advanced Book Program.

[11] Neto, R.O., Souza, L.E. and Petter, C.O., 2014. Evaluation of integrated municipal solid waste in Brazil compared to developed countries. Monografias Ambientais, 13(4), pp.37023712.

[12] Population Reference Bureau, 2013. World Population Factsheet 2013. http://www.prb.org/pdf14/2014-world-population-datasheet_eng.pdf. [5 Julay 2017].

[13] Saaty, T.L., 1987. Fundamentals of decision making and priority theory with the analytic hierarchy process, Vol. VI. Universitas Pittsburgh. USA.

[14] Saif, Y. and Almansoori, A., 2014. Design and operation of water desalination supply chain using mathematical modelling approach. Desalination, 351, pp.184-201.

[15] Skulmoski, G. J., F. T. Hartman \& J. Krahn 2007. The Delphi method for graduate research. Journal of information technology education 6: 1-21.

[16] World Population Prospects - United Nations 2015. https://esa.un.org/unpd/wpp/DataQuery [5 July 2017] 